\title{
Hip fracture predicts subsequent hip fracture: a retrospective observational study to support a call to early hip fracture prevention efforts in post-fracture patients
}

\author{
Emil Schemitsch ${ }^{1}$. Jonathan D. Adachi ${ }^{2}$. Jacques P. Brown ${ }^{3}$. Jean-Eric Tarride ${ }^{4} \cdot$ Natasha Burke $^{5} \cdot$ Thiago Oliveira $^{5}$. \\ Lubomira Slatkovska ${ }^{5}$
}

Received: 21 January 2021 / Accepted: 20 July 2021 / Published online: 11 August 2021

(c) The Author(s) 2021

\begin{abstract}
Summary In this real-world retrospective cohort, subsequent hip fracture occurred in one in four patients with any initial fracture, most often after hip fracture, on average within 1.5 years. These data support the need for early post-fracture interventions to help reduce imminent hip fracture risk and high societal and humanistic costs.

Purpose This large retrospective cohort study aimed to provide hip fracture data, in the context of other fractures, to help inform efforts related to hip fracture prevention focusing on post-fracture patients.

Methods A cohort of 115,776 patients (72.3\% female) aged $>65$ (median age 81 ) with an index fracture occurring at skeletal sites related to age-related bone loss between January 1, 2011, and March 31, 2015, was identified using health services data from Ontario, Canada, and followed until March 31, 2017.

Results Hip fracture was the most common second fracture (27.8\%), occurring in $\geq 19 \%$ of cases after each index fracture site and most frequently (33.0\%) after hip index fracture. Median time to a second fracture of the hip was $\sim 1.5$ years post-index event. Patients with index hip fracture contributed the most to fracture-related initial surgeries $(64.1 \%)$ and post-surgery complications (71.9\%) and had the second-highest total mean healthcare cost per patient in the first year after index fracture $(\$ 62,793 \pm 44,438)$. One-year mortality (any cause) after index hip fracture was $26.2 \%$ vs. $15.9 \%$ in the entire cohort, and $25.9 \%$ after second hip fracture.

Conclusion A second fracture at the hip was observed in one in four patients after any index fracture and in one in three patients with an index hip fracture, on average within 1.5 years. Index hip fracture was associated with high mortality and post-surgery complication rates and healthcare costs relative to other fractures. These data support focusing on early hip fracture prevention efforts in post-fracture patients.
\end{abstract}

Keywords Osteoporosis $\cdot$ Hip fracture $\cdot$ Imminent risk $\cdot$ Real-world data $\cdot$ Mortality $\cdot$ Healthcare resource utilization

\section{Introduction}

Lubomira Slatkovska

lslatkov@amgen.com

1 Division of Orthopaedic Surgery, Western University, London, ON, Canada

2 Department of Medicine, McMaster University, Hamilton, ON, Canada

3 CHU de Québec Research Centre and Laval University, Québec, QC, Canada

4 Department of Health Research Methods, Evidence and Impact, McMaster University, Hamilton, ON, Canada

5 Amgen Canada Inc., Mississauga, ON, Canada
Hip fractures pose high societal and humanistic costs. As common as acute myocardial infarction in adults aged $\geq 80$ or in women aged $\geq 65$, hip fracture prevalence is expected to increase due to an ageing population [1,2]. They are associated with a median hospital length of stay of 13 days and high healthcare costs, predicted to increase to $\$ 2.4$ billion by 2041 in Canada alone [1, 3, 4]. Within 1 year post-hip fracture, $25 \%$ of patients become institutionalized while $50 \%$ of long-term care patients become completely dependent or die $[5,6]$. Mortality rate post-hip fracture is similar to that of acute myocardial infarction and partially related to complications of hip fracture surgery such as pneumonia, with 
in-hospital mortality having increased by two- to fourfold during the COVID-19 pandemic in various countries [7-11].

Hip fracture is a hallmark osteoporotic fracture with $70-90 \%$ of cases caused by this chronic disease [12]. Of patients with a hip fracture, $50 \%$ have a history of prior fracture at another skeletal site, yet these patients represent only $16 \%$ of the population targeted for fracture risk assessment [13]. In older adults, prior fracture is a significant predictor of a subsequent hip fracture, especially within the following 2 years [14-16]. Thus, recent clinical practice guidelines recommend considering patients with a recent fracture to be at very high risk for future fracture-known as imminent risk - and in need of a therapy efficacious enough to improve bone strength and reduce fracture risk within 2 years, followed by a maintenance therapy [17-20]. However, in Canada, only an estimated $10-20 \%$ and $28 \%$ receive fracturerisk assessment and/or management post-any fracture and post-hip fracture, respectively [21-24]. Thus, effective hip fracture prevention strategies are currently challenged by this large care gap.

Meanwhile, Canadian epidemiological studies to help inform efforts related to hip fracture prevention are lacking, with most studies conducted in the last decade focusing on pre- or postoperative management [25-30]. Thus, the primary objective of this large, real-world, retrospective cohort study of Ontarians aged $>65$ was to characterize imminent risk of hip fracture by describing the frequency, distribution and median time to subsequent hip fracture, based on the site of initial fracture. The secondary objectives were to describe the frequency and distribution of fracture-related surgeries, surgery-related complications, healthcare costs and mortality 1 year following a hip fracture, relative to other fracture sites.

\section{Methods}

This was a population-based retrospective database study conducted in Ontario, Canada (population 14.7 million), using the ICES Data Repository [31]. The primary databases used are provided in Online Resource 1. The study protocol was approved by the Advarra Institutional Review Board.

\section{Study participants}

Adults aged $>65$ years (i.e. 66 years and older) with an index fracture occurring at an osteoporotic fracture site between January 1, 2011, and March 31, 2015, were identified from hospital admissions, emergency and ambulatory care records using International Classification of Diseases (ICD)-10 diagnostic codes for fracture as a main diagnosis or admitting diagnosis (Online Resource 2). Patients were excluded if they presented with a fracture occurring at a non-osteoporotic site (i.e. skull, face, hands and feet) or associated with a trauma code (Online Resource 3), to minimize the inclusion of high-trauma fractures [32]. Patients were also excluded if they experienced a fracture during the 5 -year lookback period prior to the index fracture date to minimize the influence of a pre-index fracture on examined outcomes. Adults aged $<66$ were excluded in order to examine medication data in this cohort [4].

\section{Variables of interest and outcome measures}

Data were analysed up to March 31, 2017 (Online Resource $4)$; thus, depending on when the index fracture occurred, opportunity for follow-up was 2 (2015-2017) to 6 years (2011-2017). Index and second fractures occurring at each site were examined over the study follow-up. For second fractures, the same identification criteria were applied as for index fractures. Initial index fracture-related surgeries were assessed using Canadian Classification of Health Interventions codes over the study follow-up (Online Resource 5 ) and surgery-related complications (infections related to surgery, complications related to prosthetic devices, deep vein thrombosis and pulmonary embolism, pneumonia, myocardial infarction, stroke and cerebrovascular events, fracture resulting from surgery/periprosthetic fracture) were assessed using ICD- 9 or 10 codes $\leq 30$ days post-surgery (Online Resource 6). Death due to any cause and the following types of direct accrued healthcare utilization costs standardized to 2017 Canadian dollars (CAD) and 2017 US dollars (USD) (and recently described in more detail [4]) were assessed up to 1 year from the index date for all index fracture sites: hospitalizations (i.e. inpatient hospitalization and same-day surgery), inpatient rehabilitation, continuing care services (i.e. hospital-based continuing care, home care and long-term care), prescription drug benefit claims and other healthcare services (i.e. emergency department visits, hospital outpatient clinic visits, physician billings, physiotherapy billings and laboratory claims). One-year mortality and healthcare costs were also assessed post-second hip fracture only.

\section{Data synthesis and analysis}

Descriptive statistics were used to summarize clinical characteristics and outcomes. Outcomes are reported by each index fracture site unless otherwise indicated. Median time from index fracture of each site to second fracture of the hip was calculated. Direct 1-year healthcare utilization costs were calculated using a previously published algorithm, with the contribution of each healthcare cost type to the total cost reported [4, 33] The STROBE and RECORD statements were used to report the findings from this study.[34]. 


\section{Results}

\section{Clinical characteristics}

The cohort included 115,776 patients with an index fracture (Fig. 1), 72.3\% ( $n=83,690)$ of which were female (Table 1$)$. The mean age ( \pm standard deviation $[\mathrm{SD}])$ at the date of index fracture was $80.4( \pm 8.3)$ years with $48.8 \%$ $(n=56,441)$ of patients aged $66-80$ years. The most common comorbidities in this cohort were osteoarthritis $(76.2 \%$, $n=88,223)$, diabetes $(30.6 \%, n=35,434)$ and stroke or cerebrovascular events $(30.3 \%, n=35,030)$. The proportion of patients on any osteoporosis treatment 1 year prior to index fracture was $28.3 \%(n=32,757)$, as further described in a recent report on the same fracture cohort [35]. A hip fracture was the most common index fracture, occurring in $27.3 \%$ $(n=31,613)$ of patients (Table 1). The proportion of index hip fractures by age at index date was $66-70,6.9 \% ; 71-75$, $9.8 \%$; 76-80, $15.8 \%$; 81-85, $23.8 \%$; and $86+, 43.8 \%$.

\section{Second fracture of the hip}

Amongst patients experiencing a second fracture of any site over the study follow-up $(17.8 \%, n=20,629)$, hip fracture was the most common second fracture overall, occurring in $27.8 \%(n=5,745)$ of patients (Table 1). Hip fracture was the most common second fracture after each index fracture site, except after a radius/ulna fracture where hip was the second most common (hip, $19.4 \%, n=189$ vs. wrist, $25.0 \%$, $n=243$ ) (Fig. 2A). Hip fracture occurred as the second fracture in $\geq 19 \%$ of patients for all index fracture sites, most often after hip index fracture $(33.0 \%, n=1,660$; Fig. 2B). The proportion of second hip fractures by age at index date was $66-70,6.2 \%$; 71-75, 9.6\%; 76-80, 16.7\%; 81-85, $26.0 \%$; and $86+, 41.4 \%$.

Median time from index fracture of any site to second fracture of the hip over the study follow-up was approximately 1.5 years (554 [interquartile range (IQR) 252-941] days) (Fig. 2B). When the index fracture occurred at the hip, the median time from index to second hip fracture was also approximately 1.5 years (566 [IQR 287-938] days). Median time to second fracture of the hip was the shortest after femur (397 [IQR 192-867] days), pelvis (484 [IQR 217-869] days) and vertebral (clinical; 493 [IQR 218-888] days) index fractures.

\section{Contribution of index hip fractures to surgeries, complications and 1-year mortality}

Amongst all patients requiring initial index fracture-related surgery $(38.8 \%, n=44,949)$ and those experiencing complications 30 days post-surgery $(19.7 \%, n=8868)$, the majority had an index hip fracture $(64.1 \%, n=28,790$ and $71.9 \%$, $\mathrm{n}=6379$, respectively) (Fig. 3). An index hip fracture was associated with the highest proportion of patients undergoing initial surgery (91.4\%), followed by femur fracture (80.6\%), and the second-highest experiencing complications (22.2\%), preceded by femur fracture (35.8\%). Mortality at 1 year (due to any cause) in the entire fracture cohort was $15.9 \%(n=18,392)$. Index hip fracture was associated with the highest 1 -year mortality rate $(26.2 \%, n=8289)$ and contributed to the most deaths $(45.1 \%)$ of all index fracture sites
Fig. 1 Flow diagram of patients included in the cohort. ${ }^{\mathrm{a}} \mathrm{All}$ patients with a valid IKN with a fracture occurring at an osteoporotic fracture site (hip, vertebral [clinical], wrist [distal radius, or both distal radius and ulna], clavicle/ribs/sternum, humerus, tibia/fibula/knee [including medial and lateral malleolus], pelvis, radius/ulna [proximal, midshaft or distal ulna only], multisite, femur) between January 1, 2011, and March 31, 2015. Fractures were identified using ICD-10-CA codes from hospital admissions, emergency room visits and ambulatory care. $I C D-10-C A$ International Classification of Diseases, 10th revision, Canada, IKN ICES key number

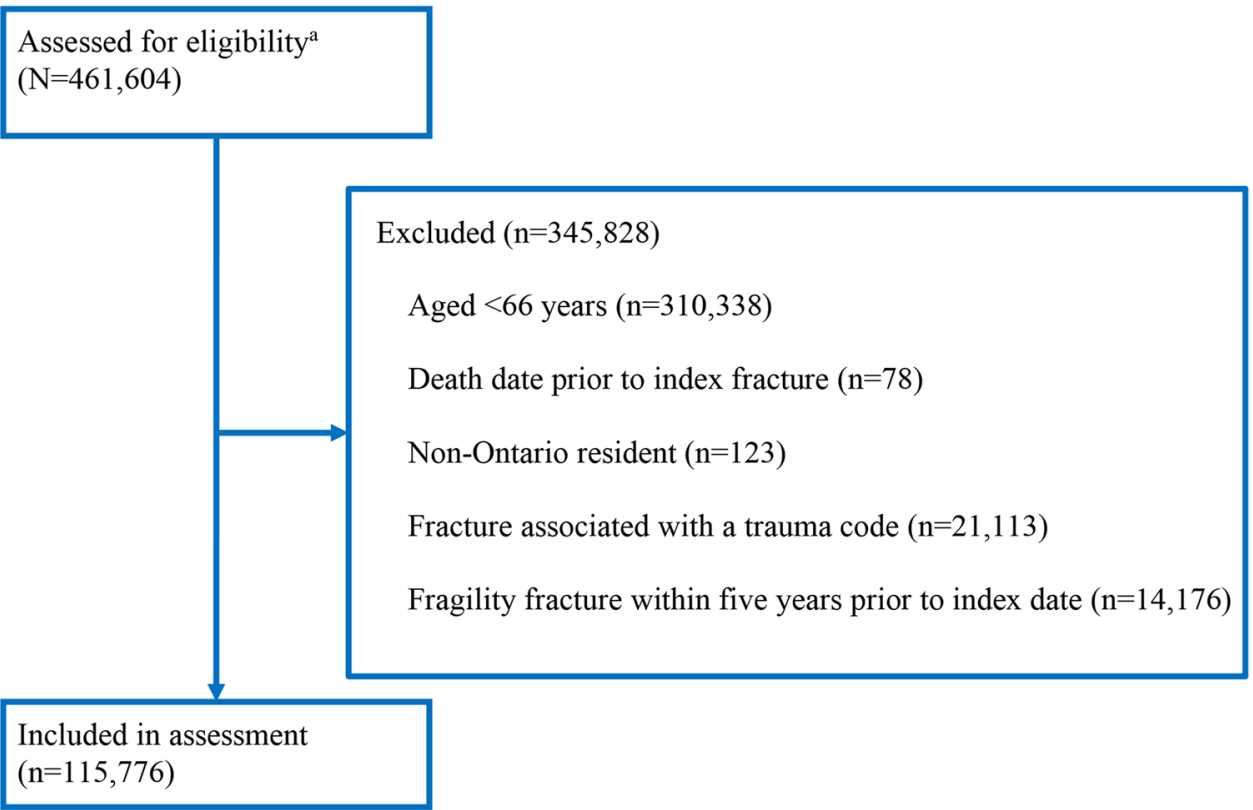


Table 1 Clinical characteristics of the index fracture cohort

\begin{tabular}{|c|c|}
\hline Characteristic & $n(\%)$ \\
\hline Total number of patients & 115,776 \\
\hline \multicolumn{2}{|l|}{ Sex } \\
\hline Female & $83,690(72.3 \%)$ \\
\hline Male & $32,086(27.7 \%)$ \\
\hline \multicolumn{2}{|l|}{ Age } \\
\hline Mean \pm SD & $80.4 \pm 8.28$ \\
\hline Median (IQR) & $81(74-87)$ \\
\hline $66-70$ years & $17,998(15.5 \%)$ \\
\hline $71-75$ years & $17,847(15.4 \%)$ \\
\hline $76-80$ years & $20,596(17.8 \%)$ \\
\hline $81-85$ years & $24,119(20.8 \%)$ \\
\hline$\geq 86$ years & $35,216(30.4 \%)$ \\
\hline \multicolumn{2}{|l|}{ Respiratory conditions $^{\mathrm{a}}$} \\
\hline Asthma & $17,538(15.1 \%)$ \\
\hline COPD & $33,485(28.9 \%)$ \\
\hline \multicolumn{2}{|l|}{ Inflammatory conditions ${ }^{\mathrm{a}}$} \\
\hline Rheumatoid arthritis & $4459(3.9 \%)$ \\
\hline Psoriasis & $8076(7.0 \%)$ \\
\hline Spondyloarthritis & $5084(4.4 \%)$ \\
\hline Osteoarthritis $^{\mathrm{a}}$ & $88,223(76.2 \%)$ \\
\hline Cancer $^{\mathrm{a}}$ & $8390(7.2 \%)$ \\
\hline Chronic kidney disease $^{\mathrm{a}}$ & $13,757(11.9 \%)$ \\
\hline Diabetes $^{\mathrm{a}}$ & $35,434(30.6 \%)$ \\
\hline \multicolumn{2}{|l|}{ Vascular events $^{\mathrm{a}}$} \\
\hline Myocardial infarction & $8175(7.1 \%)$ \\
\hline Stroke or cerebrovascular events & $35,030(30.3 \%)$ \\
\hline Dementia $^{\mathrm{a}}$ & $24,092(20.8 \%)$ \\
\hline \multicolumn{2}{|l|}{ Osteoporosis treatment type ${ }^{b}$} \\
\hline Any treatment & $32,757(28.3 \%)$ \\
\hline Denosumab & $1578(1.4 \%)$ \\
\hline Bisphosphonate & $29,030(25.1 \%)$ \\
\hline Raloxifene & $656(0.6 \%)$ \\
\hline HRT & $3597(3.1 \%)$ \\
\hline Steroid use ${ }^{\mathrm{a}}$ & $3340(2.9 \%)$ \\
\hline Opioid use $^{\mathrm{a}}$ & $34,834(30.1 \%)$ \\
\hline \multicolumn{2}{|l|}{ Fracture treatment location } \\
\hline Urban & $103,720(89.6 \%)$ \\
\hline Rural & $10,626(9.2 \%)$ \\
\hline Missing & $1430(1.2 \%)$ \\
\hline \multicolumn{2}{|l|}{ Index fracture by site ${ }^{c}$} \\
\hline Hip & $31,613(27.3 \%)$ \\
\hline Wrist (distal radius, or both distal radius and ulna) & $17,859(15.4 \%)$ \\
\hline Clavicle/ribs/sternum & $14,559(12.6 \%)$ \\
\hline Humerus & $13,237(11.4 \%)$ \\
\hline Tibia/fibula/knee (including medial and lateral malleolus) & $10,894(9.4 \%)$ \\
\hline Pelvis & $8328(7.2 \%)$ \\
\hline Vertebral (clinical) & $7721(6.7 \%)$ \\
\hline Radius/ulna (proximal, midshaft or distal ulna only) & $4828(4.2 \%)$ \\
\hline Multisite & $3735(3.2 \%)$ \\
\hline Femur & $3002(2.6 \%)$ \\
\hline Any site & $115,776(100 \%)$ \\
\hline
\end{tabular}


Table 1 (continued)

\begin{tabular}{ll}
\hline Characteristic & $n(\%)$ \\
\hline Second fracture by site $^{\text {d }}$ & \\
Hip & $5745(27.8 \%)$ \\
Clavicle/ribs/sternum & $2460(11.9 \%)$ \\
Wrist (distal radius, or both distal radius and ulna) & $2249(10.9 \%)$ \\
Humerus & $2088(10.1 \%)$ \\
Pelvis & $1977(9.6 \%)$ \\
Vertebral & $1819(8.8 \%)$ \\
Multisite & $1518(7.4 \%)$ \\
Tibia/fibula/knee (including medial and lateral malleolus) & $1317(6.4 \%)$ \\
Radius/ulna (proximal, midshaft or distal ulna only) & $741(3.6 \%)$ \\
Femur & $715(3.6 \%)$ \\
Any site & $20,629(100 \%)$ \\
\hline
\end{tabular}

Values reported as $n(\%)$ unless otherwise indicated

$C O P D$ chronic obstructive pulmonary disease, $H R T$ hormone replacement therapy, $I Q R$ interquartile range, $S D$ standard deviation

${ }^{a}$ Time frame for cancer was 5 years within index date and, for all other comorbidities and non-osteoporotic medications, was any time prior to index date

${ }^{\mathrm{b}}$ Within 1 year of index date. Bisphosphonates include alendronate, cyclical etidronate, risedronate or zoledronic acid. Denosumab is not publicly covered in men and teriparatide in men or women in Ontario

${ }^{\mathbf{c}}$ Percent of total number of index fracture cases $(N=115,776)$ from January 1, 2011, to March 31, 2015. Reported from highest to lowest number. Patients with multisite fractures were analysed as their own group; they were not double-counted, and no site was prioritized. The ICD-10 codes used to identify fracture sites are listed in Online Resource 2

${ }^{\mathrm{d}}$ Percent of total number of second fracture cases $(N=20,629)$ from the date of index event to March 31 , 2017. Reported from highest to lowest number. Fracture of the same site that was dated within 91 days of the index fracture was assumed to stem from the same fracture and was not counted as a second fracture. The anatomical location of multisite index fracture was used to exclude a second single-site fracture occurring in a similar location within 91 days. The ICD-10 codes used to identify fracture sites are listed in Online Resource 2

(Fig. 3). Second hip fracture was associated with a $25.9 \%$ $(n=1488)$ 1-year mortality rate.

\section{Contribution of hip fracture to healthcare utilization cost}

Mean \pm SD total healthcare cost across all index fracture sites was $\$ 39,089 \pm 43,272(\$ 29,853 \pm \$ 33,048$ in 2017 USD) per patient in the first year post-fracture. An index hip fracture had the second highest mean total healthcare cost of $\$ 62,793 \pm 44,438(\$ 47,957 \pm \$ 33,939$ in 2017 USD), closely after a femur index fracture $(\$ 65,489 \pm 54,116$ in 2017 CAD; $\$ 50,016 \pm \$ 41,330$ in 2017 USD). The contribution of each type of healthcare cost after an index hip fracture was highest for hospitalizations (39\%) and continuing care (32\%), with less than one-third of total costs resulting from other healthcare services (14\%), inpatient rehabilitation (11\%) and prescription drug benefit claims (3\%). The mean length of hospitalization stay decreased from 2011 (15.9 days) to 2015 (13.0 days). When the second fracture was a hip fracture, mean total first-year healthcare costs ranged \$59,935-69,518
( $\pm 43,739-45,893 ; \$ 45,774-\$ 53,093[ \pm \$ 33,405-\$ 35,050]$ in 2017 USD) depending on index fracture site.

\section{Interpretation}

Hip fracture was the most common second fracture in this fracture cohort of patients aged $>65$, occurring in one in four over 2 to 6 years of follow-up. An incident hip fracture was the most predictive of a second hip fracture, occurring in $33 \%$ of patients and within $\sim 1.5$ years in half of these cases. However, the risk of second hip fracture was consistently $\geq 19 \%$ over a median time of $<2$ years across index fracture sites. Considering a 3\% 10-year hip fracture risk is a high-risk threshold recommended by clinical practice guidelines [18], this is an important finding informing hip fracture prevention efforts to focus on all osteoporotic-related fracture sites as part of secondary hip fracture prevention [35]. Patients with an index hip fracture also accounted for the most deaths, surgeries and post-surgery complications within the first year post-fracture, and 1-year mortality rate after index hip fracture was the highest amongst all fracture 
Fig. 2 Second fracture of the hip based on index fracture site. A Distribution of second fracture based on index fracture site. ${ }^{\text {a }}$ The most common second fracture site for a given index fracture. ${ }^{b}$ Percentages based on total number of patients with an index fracture occurring at a given site. Values at the top of each bar represent \% (number) of second fracture of any site. ${ }^{\mathrm{c}}$ Index fracture occurring at major osteoporotic fracture site. B Median time to second hip fracture based on index fracture site. ${ }^{\text {aPercentages based on the }}$ total number of second fractures in a given index fracture site. $I Q R$ interquartile range

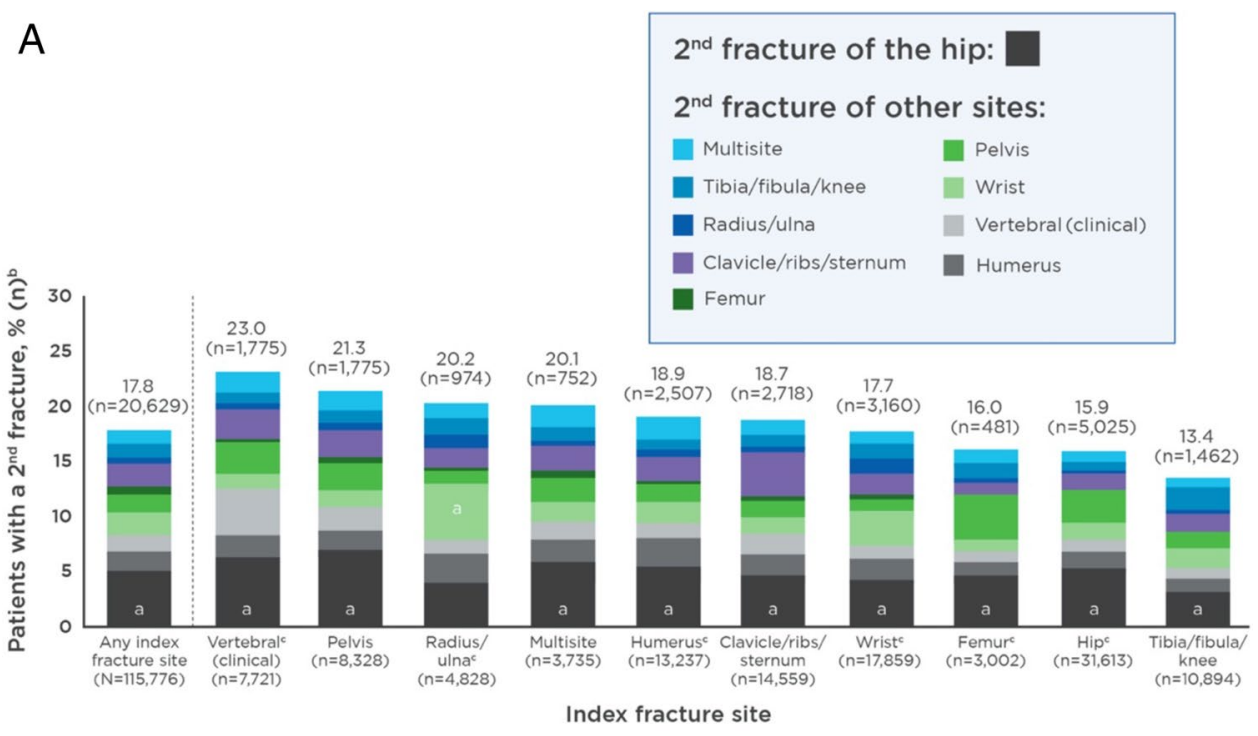

B sites examined. A hip fracture also accrued the second highest healthcare cost within the first year post-fracture, closely after femur fracture, in part due to high hospitalization and continuing care costs. Finally, although hip fractures are most common in geriatric patients, younger patients' risk cannot be overlooked considering one in three of index or second hip fracture cases were observed in patients aged 66-80.

Our observed $33 \%$ rate of a second hip fracture following an incident hip fracture over 2 to 6 years of follow-up was similar to that of $34 \%$ observed in another Canadian fracture cohort over 10 years of follow-up (aged $\geq 60$, during 1990-2005) [36]. Observing a similar rate over a shorter follow-up is in line with prior studies of imminent fracture risk reporting subsequent fractures cluster in time after an incident fracture, wherein $61 \%$ of subsequent hip fractures followed over 10 years were reported to occur within the initial 2 years after an incident fracture [19, 37]. However, the imminent risk of hip fracture is currently not well-documented, as prior studies have primarily examined imminent risk of any fracture [38, 39]. A study of Canadians aged $\geq 66$ observed a 1.6- to 6.5-fold higher risk of subsequent hip or femur fracture within 1 year after an incident fracture, with higher risks in men and younger age categories [16]. Studies reporting absolute imminent risks in US fracture cohorts aged $\geq 65$ observed $4.8 \%$ of women and $1.4 \%$ of all adults experienced a subsequent hip fracture within 2 years after a prior fracture $[15,40]$. Only one study reported imminent risk of hip fracture after an incident hip fracture in adults aged $\geq 65$ and observed lower rates than those in our cohort, of $4 \%$ and $9 \%$ within 2 and 5 years, respectively [15]. This study also found spine, humerus or clavicle fracture was most predictive of a subsequent hip fracture, rather than incident hip fracture. This US fracture cohort had a similar age 
Fig. 3 Contribution of index hip fractures to the total number of patients undergoing initial surgery, experiencing complications or to 1-year mortality. ${ }^{\text {aPercentages based }}$ on the number of patients who experienced $\geq 1$ post-surgery complication within 30 days
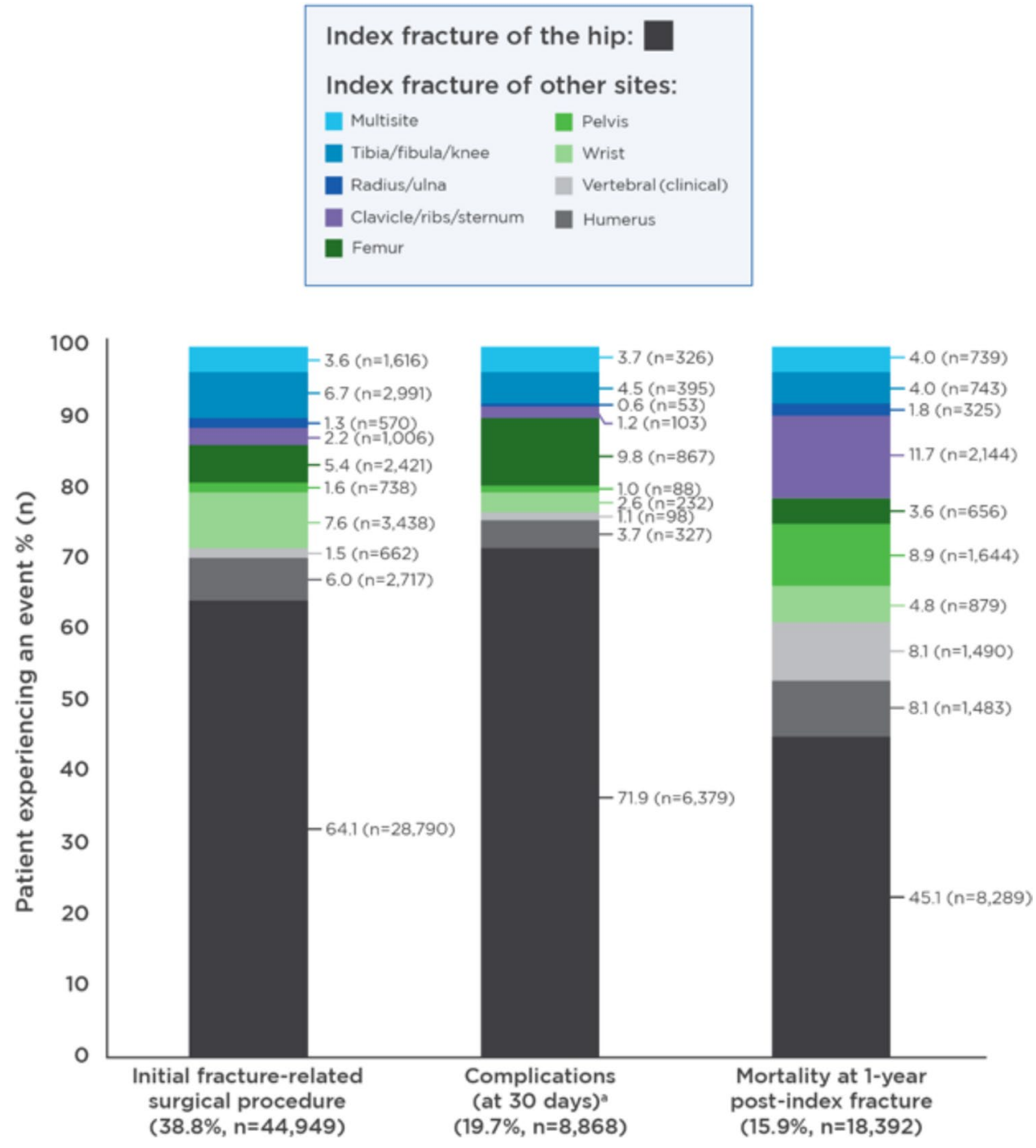

distribution as our cohort but perhaps differed in hip fracture risk due to cultural differences, only examining women, and observing a much higher proportion of vertebral index fractures (28.9\%). As such, country-specific studies of imminent risk of hip fracture after an incident hip fracture are needed.

Our data also contribute to evidence of high mortality and direct healthcare costs following hip fractures. Hip fracture was previously observed to have the highest mortality rate amongst other fracture sites in adults aged $\geq 50$ [41]. Consistent with our observed $26 \%$ rate, 1-year mortality following a hip fracture was reported in $22 \%$ of women and $33 \%$ of men in a similar Canadian cohort [32]. We observed a similar 1-year mortality rate after second hip fracture, unlike another study of Canadians (aged $\geq 60$ ) showing a higher monthly mortality rate after index vs. second hip fracture (16.2 vs. 21.1 per 1000) over longer follow-up (1990-2005) and with a smaller proportion of second hip fractures (7\%) $[32,42]$. The vulnerability of hip fracture patients was also recently highlighted in studies from Europe and the USA showing the short-term $(<12$-week) mortality rate increased by two- to four-fold in all hip fracture patients during the COVID-19 pandemic, reaching 30-56\% in COVID- $19^{+}$hip fracture patients [8-11]. In light of these findings, future research is needed to assess mortality rate after second vs. index fracture and during the COVID-19 pandemic in Canada. Further, while we observed a hip fracture accrues the second highest healthcare costs, albeit closely after a femur fracture (as recently described in more detail [4]), prior studies observed it culminates in the greatest costs amongst other fracture sites [43, 44]. As in our study, a 2013 study of Ontarians aged $\geq 65$ showed hospitalizations, and continuing care costs and rehabilitation were the primary drivers behind healthcare costs associated with hip fractures, with prescription drugs accounting for $<5 \%$ [32]. Meanwhile, to our knowledge, the contribution of hip fracture to surgeries and complications relative to other fractures sites has not been documented in other recent studies. 
This Canadian epidemiological study can help inform current efforts related to hip fracture prevention, particularly those focusing on post-fracture patients. Hip fracture data was reported in the context of other fracture sites related to chronic bone loss due to ageing, and data was drawn from a province contributing to approximately one-third of fractures in Canada [45]. However, this study examined patients aged $>65$ and almost one-third of patients were aged $\geq 86$, which limits the generalizability of the results to the full population at risk of fracture (i.e. aged $\geq 50$ [45]). By excluding patients who had another fracture 5 years prior to their index event, but not beyond, the cohort was potentially biased towards an older population, resulting in a mean age roughly 5 years higher than expected for adults aged $>65$ [16]. Further, particularly vertebral fractures may be underestimated in this cohort considering only the 'Most Responsible Diagnosis' and 'Pre-Admit Comorbidity' were used to identify index fractures. Also, as in prior healthcare database research, the determination of fracture was based on the exclusion of high-trauma ICD codes and not independent adjudication of low-trauma fractures [32]. However, this may not be a limitation of the current study since recent research suggests both low- and high-trauma fractures are predictive of future fracture [46, 47]. Finally, future studies should assess surgeries and complications after second hip fracture too, as well as include other common post-surgery complications not included in the current study (e.g. urinary infection).

\section{Conclusion}

In this large, fracture cohort of adults aged $>65$, a second fracture of the hip was observed in one in four patients with any index fracture and in one in three patients with an index hip fracture, on average within 1.5 years over 2 to 6 years of follow-up. Index hip fracture was associated with high mortality and post-surgery complication rates and healthcare costs relative to other fractures. These data further support early hip fracture prevention strategies focusing on adults aged $\geq 65$ with a recent fracture to help reduce imminent hip fracture risk and high societal and humanistic costs.

Supplementary Information The online version contains supplementary material available at https://doi.org/10.1007/s00198-021-06080-5.

Acknowledgements This study made use of de-identified data from the ICES Data Repository, managed by the ICES with support from its funders and partners: Canada's Strategy for Patient-Oriented Research (SPOR), the Ontario SPOR Support Unit, the Canadian Institutes of Health Research and the Government of Ontario. The opinions, results and conclusions reported are those of the authors. No endorsement by ICES or any of its funders or partners is intended or should be inferred. Parts of this material are based on data and information compiled and provided by CIHI. However, the analyses, conclusions, opinions and statements expressed herein are those of the author, and not necessarily those of CIHI.

Author contributions ES, JAD, JPB, JET, NB, TO and LS contributed to design of the study, review and interpretation of the data and drafting and review of the manuscript.

Funding This study was funded by Amgen Canada Inc. including design of the study and analysis and interpretation of data. Data collection was performed by ICES and sponsored by Amgen Canada Inc. Editorial assistance was provided by MEDUCOM Health Inc. and funded by Amgen Canada Inc.

Data availability The datasets generated during and/or analysed during the current study are available in the ICES repository upon request. The data that support the findings of this study are available from ICES. However, restrictions apply to the availability of these data, which were used under license for the current study and therefore are not publicly available [https://www.ices.on.ca/Data-and-Privacy/ICES-data]. Data are however available from the authors upon reasonable request and with permission from ICES.

Code availability Not applicable.

\section{Declarations}

Conflict of interest ES has received consulting fees from Acumed LLC, Amgen, Implants for Trauma Surgery, Pentopharm, SanofiAventis, Smith \& Nephew, Stryker, Swemac; received grant/research support from Amgen, Biocomposites, Smith \& Nephew. JDA has received consulting fees from Amgen; received grant/research support from AbbVie, Amgen, Celgene, Eli Lilly, Pfizer, Radius. JPB has received consulting fees and honoraria from Amgen and Servier; received research funding from Mereo BioPharma, Radius Health, Servier; served on speakers' bureau for Amgen. JET has received consulting fees from Amgen, Analytica Laser International, AstraZeneca, Bayer, Edwards Lifesciences, Eli Lilly, The European Commission Initiative on Breast Cancer, Evidera, Flatiron, GSK, Merck, Novartis, PCDI Canada, Pfizer, Roche; received grant/research support from Amgen, Assurex/Myriad, AstraZeneca, CSL Behring, Edwards Lifesciences, Novo Nordisk, Sage; served on speakers' bureau for Allergan. TO, NB and LS are employees and own stock in Amgen.

Ethical approval The study protocol was approved by the Advarra Institutional Review Board.

Consent to participate Formal consent is not required for this type of study.

Consent for publication Not applicable.

Open Access This article is licensed under a Creative Commons Attribution-NonCommercial 4.0 International License, which permits any non-commercial use, sharing, adaptation, distribution and reproduction in any medium or format, as long as you give appropriate credit to the original author(s) and the source, provide a link to the Creative Commons licence, and indicate if changes were made. The images or other third party material in this article are included in the article's Creative Commons licence, unless indicated otherwise in a credit line to the material. If material is not included in the article's Creative Commons licence and your intended use is not permitted by statutory regulation or exceeds the permitted use, you will need to obtain permission 
directly from the copyright holder. To view a copy of this licence, visit http://creativecommons.org/licenses/by-nc/4.0/.

\section{References}

1. Wiktorowicz ME, Goeree R, Papaioannou A, Adachi JD, Papadimitropoulos E (2001) Economic implications of hip fracture: health service use, institutional care and cost in Canada. Osteoporos Int 12(4):271-278

2. Canadian Chronic Disease Surveillance System (CCDSS) (2016) https://health-infobase.canada.ca/ccdss/data-tool/Age?G=00\&V= 9\&M=4 Accessed 19 Aug 2020.

3. Cram P, Lix LM, Bohm E, Yan L, Roos L, Matelski J et al (2019) Hip fracture care in Manitoba, Canada and New York State, United States: an analysis of administrative data. CMAJ Open 7(1):E55-E62

4. Tarride J, Adachi JD, Brown JP, Schemitsch E, Slatkovska L, Burke N (2021) Incremental costs of fragility fractures: a population-based matched-cohort study from Ontario, Canada. Osteoporos Int. https://doi.org/10.1007/s00198-021-05877-8

5. Morin S, Lix LM, Azimaee M, Metge C, Majumdar SR, Leslie WD (2012) Institutionalization following incident nontraumatic fractures in community-dwelling men and women. Osteoporos Int 23(9):2381-2386

6. Neuman MD, Silber JH, Magaziner JS, Passarella MA, Mehta S, Werner RM (2014) Survival and functional outcomes after hip fracture among nursing home residents. JAMA Intern Med 174(8):1273-1280

7. Kaul P, Armstrong PW, Chang WC, Naylor CD, Granger CB, Lee KL et al (2004) Long-term mortality of patients with acute myocardial infarction in the United States and Canada: comparison of patients enrolled in Global Utilization of Streptokinase and t-PA for Occluded Coronary Arteries (GUSTO)-I. Circulation 110(13):1754-1760

8. Konda SR, Ranson RA, Solasz SJ, Dedhia N, Lott A, Bird ML et al (2020) Modification of a validated risk stratification tool to characterize geriatric hip fracture outcomes and optimize care in a post-COVID-19 world. J Orthop Trauma 34(9):e317-e324

9. LeBrun DG, Konnaris MA, Ghahramani GC, Premkumar A, DeFrancesco CJ, Gruskay JA et al (2020) Hip fracture outcomes during the COVID-19 pandemic: early results from New York. J Orthop Trauma 34(8):403-410

10. Kayani B, Onochie E, Patil V, Begum F, Cuthbert R, Ferguson $D$ et al (2020) The effects of COVID-19 on perioperative morbidity and mortality in patients with hip fractures. Bone $\mathrm{Jt} \mathrm{J}$ 102-B(9):1136-1145

11. Muñoz Vives JM, Jornet-Gibert M, Cámara-Cabrera J, Esteban PL, Brunet L, Delgado-Flores L et al (2020) Mortality rates of patients with proximal femoral fracture in a worldwide pandemic: preliminary results of the Spanish HIP-COVID observational study. J Bone Jt Surg Am 102(13):e69

12. Osteoporosis Canada. Fast facts. https://osteoporosis.ca/aboutthe-disease/fast-facts. Accessed 19 Nov 2020

13. International Osteoporosis Foundation. Capture of the fracture: identifying patients. https://www.capturethefracture.org/ident ifying-patients. Accessed 19 Nov 2020

14. Centre for Metabolic Bone Diseases, University of Sheffield, UK. Fracture Risk Assessment Tool (FRAX). https://www.sheff ield.ac.uk/FRAX/tool.aspx? country=19. Accessed 19 Nov 2020

15. Balasubramanian A, Zhang J, Chen L, Wenkert D, Daigle SG, Grauer A et al (2019) Risk of subsequent fracture after prior fracture among older women. Osteoporos Int 30(1):79-92

16. Beaudoin C, Jean S, Moore L, Gamache P, Bessette L, SteMarie LG (2018) Number, location, and time since prior fracture as predictors of future fracture in the elderly from the general population. J Bone Miner Res 33(11):1956-1966

17. Eastell R, Rosen CJ, Black DM, Cheung AM, Murad MH, Shoback D (2019) Pharmacological management of osteoporosis in postmenopausal women: an Endocrine Society clinical practice guideline. J Clin Endocrinol Metab 104(5):1595-1622

18. Camacho PM, Petak SM, Binkley N, Diab DL, Eldeiry LS, Farooki A et al (2020) American Association of Clinical Endocrinologists/American College of Endocrinology clinical practice guidelines for the diagnosis and treatment of postmenopausal osteoporosis: 2020 update. Endocr Pract 26(5):564-570

19. Kanis JA, Harvey NC, McCloskey E, Bruyère O, Veronese N, Lorentzon $\mathrm{M}$ et al (2020) Algorithm for the management of patients at low, high and very high risk of osteoporotic fractures. Osteoporos Int 31(1):1-12

20. Shoback D, Rosen CJ, Black DM, Cheung AM, Murad MH, Eastell R (2020) Pharmacological management of osteoporosis in postmenopausal women: an Endocrine Society guideline update. J Clin Endocrinol Metab 105(3):587

21. Papaioannou A, Giangregorio L, Kvern B, Boulos P, Ioannidis G, Adachi JD (2004) The osteoporosis care gap in Canada. BMC Musculoskelet Disord 5:11

22. Bessette L, Ste-Marie LG, Jean S, Davison KS, Beaulieu M, Baranci $M$ et al (2008) The care gap in diagnosis and treatment of women with a fragility fracture. Osteoporos Int 19(1):79-86

23. Papaioannou A, Kennedy CC, Ioannidis G, Gao Y, Sawka AM, Goltzman D et al (2008) The osteoporosis care gap in men with fragility fractures: the Canadian Multicentre Osteoporosis Study. Osteoporos Int 19(4):581-587

24. Ontario Osteoporosis Strategy (2017) Provincial performance data for osteoporosis management. https://www.osteostrategy.on.ca/ wp-content/uploads/Final-OP-Provincial-Performance-StatusReport-Apr-2017-1.pdf. Accessed 19 Nov 2020.

25. Sheehan KJ, Sobolev B, Guy P, Kuramoto L, Morin SN, Sutherland JM et al (2016) In-hospital mortality after hip fracture by treatment setting. CMAJ 188(17-18):1219-1225

26. McIsaac DI, Abdulla K, Yang H, Sundaresan S, Doering P, Vaswani SG et al (2017) Association of delay of urgent or emergency surgery with mortality and use of health care resources: a propensity score-matched observational cohort study. CMAJ 189(27):E905-E912

27. Pincus D, Wasserstein D, Ravi B, Byrne JP, Huang A, Paterson JM et al (2018) Reporting and evaluating wait times for urgent hip fracture surgery in Ontario, Canada. CMAJ 190(23):E702-E709

28. Sobolev B, Guy P, Sheehan KJ, Kuramoto L, Sutherland JM, Levy AR et al (2018) Mortality effects of timing alternatives for hip fracture surgery. CMAJ 190(31):E923-E932

29. Watt JA, Gomes T, Bronskill SE, Huang A, Austin PC, Ho JM et al (2018) Comparative risk of harm associated with trazodone or atypical antipsychotic use in older adults with dementia: a retrospective cohort study. CMAJ 190(47):E1376-E1383

30. Cho N, Boland L, McIsaac DI (2019) The association of female sex with application of evidence-based practice recommendations for perioperative care in hip fracture surgery. CMAJ 191(6):E151-E158

31. ICES. ICES 2020 data. https://www.ices.on.ca/Data-and-Privacy/ ICES-data. Accessed 20 July 2017

32. Nikitovic M, Wodchis WP, Krahn MD, Cadarette SM (2013) Direct health-care costs attributed to hip fractures among seniors: a matched cohort study. Osteoporos Int 24(2):659-669

33. Wodchis WP, Bushmeneva K, Nikitovic M, McKillop I (2013) Guidelines on person-level costing using administrative databases in Ontario. Working Paper Series, vol 1. Health System Performance Research Network, Ontario

34. Benchimol EI, Smeeth L, Guttmann A, Harron K, Moher D, Petersen I et al (2015) The REporting of studies conducted using 
observational routinely-collected health data (RECORD) statement. PLoS Med 12(10):e1001885

35. Adachi JD, Brown JP, Schemitsch E, Tarride JE, Brown V, Bell AD et al (2021) Fragility fracture identifies patients at imminent risk for subsequent fracture: real-world retrospective database study in Ontario, Canada. BMC Musculoskelet Disord 22(1):224

36. Sobolev B, Sheehan KJ, Kuramoto L, Guy P (2015) Risk of second hip fracture persists for years after initial trauma. Bone 75:72-76

37. van Geel TA, van Helden S, Geusens PP, Winkens B, Dinant GJ (2009) Clinical subsequent fractures cluster in time after first fractures. Ann Rheum Dis 68(1):99-102

38. Adachi JD, Berger C, Barron R, Weycker D, Anastassiades TP, Davison KS et al (2019) Predictors of imminent non-vertebral fracture in elderly women with osteoporosis, low bone mass, or a history of fracture, based on data from the population-based Canadian Multicentre Osteoporosis Study (CaMos). Arch Osteoporos 14(1):53

39. Yusuf AA, Hu Y, Chandler D, Crittenden DB, Barron RL (2020) Predictors of imminent risk of fracture in Medicare-enrolled men and women. Arch Osteoporos 15(1):120

40. Sheer RL, Barron RL, Sudharshan L, Pasquale MK (2020) Validated prediction of imminent risk of fracture for older adults. Am J Manage Care 26(3):e91-e97

41. Tran T, Bliuc D, van Geel T, Adachi JD, Berger C, van den Bergh $\mathrm{J}$ et al (2017) Population-wide impact of non-hip non-vertebral fractures on mortality. J Bone Miner Res 32(9):1802-1810
42. Sobolev B, Sheehan KJ, Kuramoto L, Guy P (2015) Excess mortality associated with second hip fracture. Osteoporos Int 26(7):1903-1910

43. Hopkins RB, Burke N, Von Keyserlingk C, Leslie WD, Morin SN, Adachi JD et al (2016) The current economic burden of illness of osteoporosis in Canada. Osteoporos Int 27(10):3023-3032

44. Tarride JE, Hopkins RB, Leslie WD, Morin S, Adachi JD, Papaioannou A et al (2012) The burden of illness of osteoporosis in Canada. Osteoporos Int 23(11):2591-2600

45. Public Health Agency of Canada (2020) Osteoporosis and related fractures in Canada: report from the Canadian Chronic Disease Surveillance System, 2020. https://www.canada.ca/en/publichealth/services/publications/diseases-conditions/osteoporosisrelated-fractures-2020.html. Accessed 15 Jan 2021

46. Cummings SR, Eastell R (2020) Stop (mis)classifying fractures as high- or low-trauma or as fragility fractures. Osteoporos Int 31(6): 1023-1024

47. Leslie WD, Schousboe JT, Morin SN, Martineau P, Lix LM, Johansson $\mathrm{H}$ et al (2020) Fracture risk following high-trauma versus low-trauma fracture: a registry-based cohort study. Osteoporos Int 31(6):1059-1067

Publisher's note Springer Nature remains neutral with regard to jurisdictional claims in published maps and institutional affiliations. 